\title{
Review of Technical Requirements for Brazilian Distributions Companies for the Integration of Distributed Generators - A Comparative Analysis on the Perspective of IEEE-Std 1547-2
}

\author{
J.R.C de Almeida ${ }^{1}$, M.J.B.B. Davi ${ }^{1}$, C. B. dos $\operatorname{Santos}^{1}$, F. A. M. Moura ${ }^{1}$, J. R. Camacho ${ }^{2}$ \\ ${ }^{1}$ Universidade Federal do Triângulo Mineiro, Electrical Engineering Departament, Uberaba- Minas Gerais, Brazil \\ julianaramosca@ hotmail.com, moisesjr20@ hotmail.com, caio.borgess@ hotmail.com, fabricio@eletrica.uftm.edu.br \\ ${ }^{2}$ Universidade Federal de Uberlandia, School of Electrical Engineering, Uberlândia, Minas Gerais, Brazil \\ jrcamacho@ufu.br
}

\begin{abstract}
The connection of distributed generators, also known as independent generators or independent producers in the distribution systems of medium voltage or low voltage, has been widely encouraged. However, this connection lacks clear and effective regulations regarding access to technical requirements for electrical systems techniques to ensure excellence in distribution systems. Thus, this work presents a comparative analysis between the regulations of national distributors for connecting distributed generators in low and medium voltage systems, weaving a comparative analysis with IEEE 1547-2 standard (IEEE Standard for Interconnecting Distributed Resources with Electric Power Systems).
\end{abstract}

\section{Key words}

Distributed Generation, Independent Power Generation, Islanding, Independent Producer, Auto Reconnection and Energy Systems.

\section{Introduction}

The demand for electricity in Brazil is growing rapidly, thus the issue of exploitation of water resources related to concern for their scarcity are constantly cited as key to changing the energy paradigm. However, the scenario of global electricity generation has been concerned with the need to seek alternatives that can ensure the supply associated with environmental issues. In this context, Brazil presents itself as a country that has a rich energy matrix thus enabling the deployment of Distributed Generation - DG [1].

According to Normative Resolution - ANEEL 482/2012 - of the National Electric Energy Agency, Brazilian consumers can generate their own electricity from renewable sources and still provide a surplus for the distribution network [2].

Distributed generation (DG) consists of a power generation along or close to independent consumer power, technology and power supply, which connects directly to the electrical distribution system or the consumer [3]. This generation may be parallel or isolated, with the network, increasing its guaranteed supply and being also used in locations distant from the major generating plants, serves locally the consumer. This can be characterized as a mini or micro distributed generation of electricity.
Today in Brazil, there are 1625 agents investing in such markets [4].

Faced with this scenario, this paper is intended to provide guidelines for connection of the main distributors of the electricity sector, in order to understand and explain to the Fuel Cells: Technology that uses hydrogen and oxygen to generate electricity through chemical processes [6]. Reader how is made the access to the medium and low voltage systems in Brazil in relation to the technical, operational, and design requirements, information for the implementing the connection of new points of access or existing connections, and compare those standards with the IEEE 1547-2 standard. These standards seek mainly the quality of the energy distribution service, the preservation of security, efficiency and reliability of the system and the existing connections.

\section{Brazilian scenario}

With an increase in energy demand in the late 1940s we started to generate power in large power stations with the intention of generating energy at less cost, it was discouraged technological advances in the next generation of energy consumers. In recent decades, many issues such as environmental impacts, reduced availability of large hydro projects, increasing demand and rising investments in the construction of hydroelectric plants, culminated by encouraging, vigorously, the change in national energy policy. With the change this new scenario was necessary to seek new alternatives for power generation so that they could meet the present and future needs, thus emerging the distributed generation (DG) [5].

The main technologies used in distributed generation are:

Micro hydropower plants: Micro-Hydropower Plants are hydraulic micro turbines with power up to $1,000 \mathrm{~kW}$, powered by the potential energy of water.

Small Wind Farms: Small wind turbines with power up to $100 \mathrm{~kW}$, powered by the wind.

Mini plant for Cogeneration: Equipment of small size, coupled to a primary energy source powers up to $300 \mathrm{~kW}$, where it generates both heat and work, and this can be used 
to generate electricity, while the former can generate water hot, steam, process heat or cold.

Micro turbines: Small turbines with power up to $500 \mathrm{~kW}$ to generate electricity or can operate in mini cogeneration systems. Use different fuels, but the most used is natural gas or gas from landfills (biogas).

Diesel Generator: Set of diesel cycle engine coupled to an alternator/generator of electricity.

Thermal / Solar: It's the heating of water through the use of solar collectors in substitution of resistive heating water flow systems.

Photovoltaic/Solar: Generation of electricity through solar panels, made up of solar cells.

Fuel Cells: Technology that uses hydrogen and oxygen to generate electricity through chemical processes [6].

Some alternative energy sources are gaining great prominence in the Brazilian context, such as wind power, biomass and photovoltaic systems.

a) Wind Energy: has been very encouraged in Brazil showing an increasing trend since the year 2003 there were nine wind farms in operation generating $22.075 \mathrm{GW}$ with forecast for the next years of 101 wind farms to generate 6683.950GW [7] .

b) Biomass: in Brazil there are now 56 plants operating as cogeneration generating 1206.06MW. Biomass stands out as $s_{\mathrm{b}}$ the primary source of $55.8 \%$ of installed capacity, knowing that the most common form is the sugar cane bagasse. The sugarcane sector generates huge amounts of sugarcane bagasse that can be used in electricity generation [8].

c) Photovoltaic systems: due to the still high cost, photovoltaics have a small stake in the energy matrix of the developing countries. In Brazil its installed capacity in 2007 reached approximately $7800 \mathrm{MW}$.

In spite of Brazil has a lot of sunlight, it is still very small participation of photovoltaic energy in the national energy matrix.

ANEEL, in April 2012, as a way to encourage solar power generation raised the discount of $50 \%$ to $80 \%$ in the Rate of Use of the Electricity Transmission Systems (TUST) and Tariff for Use of the Electricity Distribution System (TUSD ) for solar generation projects that inject up to $30 \mathrm{MW}$ in the transmission and distribution network. Plants that begin operation until December 31, 2017 will have this discount that will last for the first 10 years of operation of the system.

We may highlight that by 2022 alternative energy sources will match $10 \%$ of installed capacity in Brazil [9].

\section{Brazilian standards for integration of distributed generation}

The new trend of the Brazilian electrical sector inserting a distributed generation in the network requires an adaptation of the electricity distribution power authorities. This connection must meet the requirements in the Distribution Procedure Module 3 - Access to the Distribution System created by ANEEL [10]. Conditions necessary for such access, information, data, technical and operational criteria, and the implementation of the connection to new generating plants and existing ones are established by this document. In addition to meeting the requirements of this document, the connected generating plants must meet the technical standards required by the power authorities. We need to prioritize the performance and quality of distribution, efficiency, reliability and preserving the security of the system and the existing service connections.

In this topic will be addressed the basic requirements of Brazilian utilities, highlighting the following power authorities: Celesc, Cemig, Coelba, Copel, Eletropaulo and Light.

We highlight some basic items that each power authority established for the insertion of DG in the network:

- Protection requirements;

- The ways of connecting the party accessing the system;

- Connection of transformers;

- Criteria for access and control highlighting the maximum power of connection per feeder and maximum number of accessing plants in the medium voltage feeder;

- Protection systems highlighting automatic reclosing and islanding.

A)Protection requirements: are highlighted five types of protection, such as solidly grounded, neutral isolated with grounded impedance, neutral effectively grounded, 3-wire solidly grounded and isolated [10]

Celesc- solidly grounded;

Cemig- solidly grounded;

Coelba- not informed;

Copel- $13.8 \mathrm{kV}$ neutral isolated with grounded impedance and $34.5 \mathrm{kV}$ neutro effectively grounded;

Eletropaulo- solidly grounded;

Light- Isolated.

B) The ways of connecting the party accessing the system: the way that the party accessing the network can be connected can vary in two ways, between feeder or exclusive transmission line for the accessing party or feeder or transmission line shared with other loads of the power utility [10]. Figures 1 and 2 show respectively, the connection via GD LT / exclusive feeder breaker using the terminal of the concessionaire and the party accessing the terminal, and the connection via exclusive GD SE.

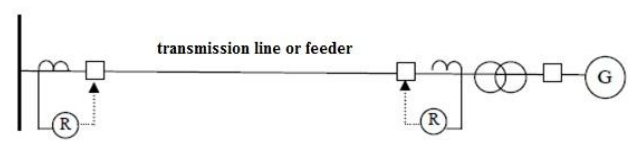

Fig.1. Connection via GD LT / exclusive feeder breaker using the terminal of the concessionaire and the party accessing the terminal.

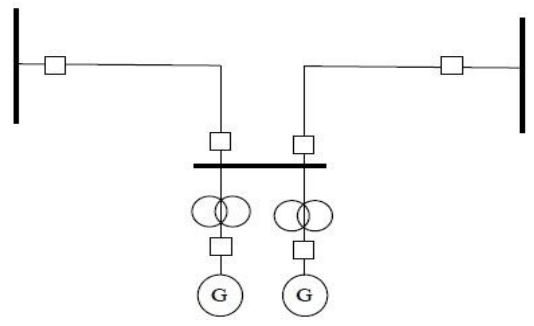

Fig.2. Connection of distributed generation via exclusive substation. 
Celesc- only medium voltage DG connections can be made either through the feeder or exclusive substations as through the outlet connection at lines. On the other hand the connection point must necessarily be party accessing the trunk feeder. In $\mathrm{HV}$, are not allowed accessing parties through outlet connections.

Cemig- MV connection, also allows connection in any configuration provided a recloser to be installed at the connection point. This recloser is transferred at no cost to the company, which has responsibility for the maintenance and operation of the equipment. On the other hand the standard connection on AT is in the drafting process, but the trend is that the connection as outlet is not allowed.

Copel- The form of connection will depend on the installed generation capacity of the accessing party, and for less than $1 \mathrm{MW}$ capacity any of the aforementioned connections might be allowed while above this value capabilities can only connect through feeders or express lines.

Coelba, Eletropaulo, and Light: there are no specific rules on how to make the connection, being needed thus to study the realization of the connection in each case. However all require the presence of a connection through a circuit breaker.

C) Connection of transformers: The type of connection of coupling or interconnection transformer to be installed between the utility and the accessing party, has great impact on how the unit of distributed generation will interact with the electrical system, especially during a short circuit. However, there is no connection universally accepted as the best to be used knowing that both options have advantages and disadvantages.

The most commonly used connections are Delta (HV) Star Grounded (LV), Star Grounded (HV) - Delta (LV) and Star - Star [10].

Celesc- Delta (HV) - Star Grounded (LV);

Cemig- Voltage $13.8 \mathrm{kV}, 24.1 \mathrm{kV}$ and $34.5 \mathrm{kV}$ use Delta (HV)

- Star Grounded (LV) and Star Grounded (HV) - Delta (LV);

Coelba- Voltage is not reported. Não é informada a tensão. Power authority Star Isolated and accessing party is not reported;

Copel- Voltage $13.8 \mathrm{kV}$ use Delta (HV) - Star Grounded (LV) and Star-Star. Voltage of 34.5kV use Delta (HV) - Star Grounded (LV), Star-Star and Star Grounded (HV) - Delta (LV);

Eletropaulo- Voltages $13.8 \mathrm{kV}, 25 \mathrm{kV}$ e $34.5 \mathrm{kV}$ use Delta (HV) - Star Grounded (LV);

Light- Voltages $13.8 \mathrm{kV}, 25 \mathrm{kV}$ e $34,5 \mathrm{kV}$ use Delta (HV) Star Grounded (LV).

D) Criteria for access control and highlighting the connection maximum power per feeder and maximum number of acessing parties in the primary feeder: The powers can range from 1 to $15 \mathrm{MW}$. Depending on each distribution company that power can change due to the level of three-phase short circuit power at the connection point. No one knows for sure the maximum number of accessing parties per feeder, but there is a criterion such that at the same connection point is added the powers of all power plants [10].

Celesc- Maximum power for 13.8, 23 and $34.5 \mathrm{kV}$ voltage: use $10 \%$ of the capacity of the three-phase short circuit connection point and use 2 acessing parties per primary feeder, for voltages of 69 and $138 \mathrm{kV}$ use more than $10 \%$ of the short-circuit capacity, but study is not needed.

Cemig- Maximum power for $13.8 \mathrm{kV}$ voltage is $7 \mathrm{MW}$ and for $23 \mathrm{kV}$ voltage is of $10 \mathrm{MW}$ and for $34.5 \mathrm{kV}$ voltage is $15 \mathrm{MW}$. It is reported the number of acessing parties to the feeder.

Coelba- It is informed neither the maximum power for 13.8 $\mathrm{kV}$ voltage and the number of acessing parties to the primary feeder.

Copel- Maximum power for voltages of 13.8 and $34.5 \mathrm{kV}$ : use $20 \%$ of the feeder power and is not told the number of acessing parties, for voltages of 69 and $138 \mathrm{kV}$ it is not informed the maximum power or the number of accessing parties to the primary feeder.

Eletropaulo- It is informed neither the maximum power for smaller than $34.5 \mathrm{kV}$ voltages nor the number of accessing parties to the primary feeder.

Light- It is informed neither the maximum power for 13.8, 25 and $34.5 \mathrm{kV}$ voltages nor the number of accessing parties to the primary feeder.

E) Protection systems highlighting islanding and automatic reclosure $(A R)$ : It is quite complex the maintenance of $\mathrm{AR}$ schemes when there distributed generation units connected to the system, which can generate risks of a switching without synchronization between generators that have met islanded loads and the power authority. In general all the power authorities point out that when there is disconnection of GD due to loss of the power authority they are not liable for damage caused to the accessing parties equipment or any other part of its electrical system due to defects, high negative sequence currents, atmospheric surges among other disturbances.

It must be included and is extremely important in the operating agreements between distribution company and the accessing party that the DG have the times of the automatic restart of the utility where it is connected, so both ends can adjust their protections more adequately [10].

Celesc- Automatic reclosing of transmission lines: quantity 2 and time of $3 \mathrm{~s}$ and automatic restart of feeders: quantity 1 and time of $5 \mathrm{~s}$.

Cemig- Automatic reclosing of transmission lines: quantity 2 and time of 3 to $175 \mathrm{~s}$ and automatic restart of feeders: quantity 2 and time of 10 to $15 \mathrm{~s}$.

Coelba- Automatic reclosing of transmission lines: quantity and time not informed and automatic restart of feeders: quantity 3 and time of 2, 5 and 10 s.

Copel- Automatic reclosing of transmission lines: quantity 2 and time of $2 \mathrm{~s}$ and automatic restart of feeders: quantity 3 and time of $0.5,6$ and $20 \mathrm{~s}$.

Eletropaulo- Automatic reclosing of transmission lines: quantity 2 and time of 1 and 15 s and automatic restart of feeders: quantity 3 and time of 1,25 and $35 \mathrm{~s}$. 
Light- Automatic reclosing of transmission lines: quantity and time not informed and automatic restart of feeders: quantity 2 and time of 3 and $15 \mathrm{~s}$.

Power authorities are very demanding when under islanded condition because it is a very complicated matter, since a careful study of the behavior of GD is necessary when servicing loads, that study is not part of the work of distribution companies and thus they need to hire specialized work force to do this study. The utility requires a high quality service and above all safe.

Figure 3 shows an islanding a generator in a power distribution network.

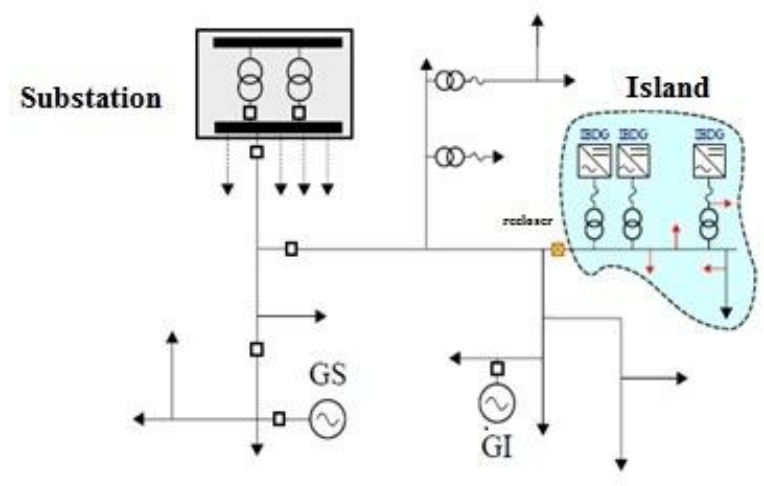

Fig.3. Islanding a generator in a power distribution network.

Celesc- The circuit breakers installed at the point of interconnection shall be triggered by secondary relays, which remove and block promptly the connection. The protection accessing party must have the ability to detect the disconnection of Celesc system, and act to prevent its generation system to operate isolated, feeding Celesc consumers [11].

Cemig- Cases of islanding is allowed only in emergency situations, so it is avoided power supply long duration interruptions [12].

Coelba- Islanding is not allowed under any circumstances [13].

Copel- Islanding operation is not allowed, but the distributed generators must afford to take his own load or part of it in specific conditions[14].

Eletropaulo- when the power authority circuit is not energized is recommended to install voltage relays that can prevent the closing of the interconnection circuit breaker [15].

Light- The DG should disconnect from the network through the anti-islanding protection in up to 2 seconds whenever the shutdown of Light network [16].

These are some recommendations on standards adopted by some Brazilian utilities so there the system operates with a quality power supply delivering energy to the consumer. In the following item will be discussed the key recommendations contained in the IEEE 1547-2 standard.

\section{IEEE 1547-2 Standard}

The IEEE 1547 standard for the interconnection of distributed generators with electric power systems was approved by the IEEE Standards Board in June 2003 and approved as national North American standard in October of the same year [17].

The 1547-2 standard provides a uniform standard for the interconnection of distributed resources with the electric power system providing important requirements for the performance, operation, safety, and interconnection maintenance.

A major concern with the connection of DG in power systems consists in their impacts. Power authorities must have a clear understanding of these impacts. These can be severe in nature due to the size and the technology used in DG, and may also be linked to the characteristics of where the DG is installed in the electric power system.

This topic will address the basic system configuration required by the standard, and the protection requirements regarding grounding reclosing and islanding.

This topic will address the basic system configuration required by the standard, and the protection requirements regarding grounding reclosing and islanding.

A) Basic system settings: consists of three phase four wire, multi-grounded star connection and single phase two-wire multi-grounded.

The system grounding controls the voltage to earth within predictable limits. Moreover, it provides a current flow which will permit the detection of an undesired connection between the system conductors and the earth. The grounding of distribution feeders is usually derived from distribution substation transformer secondary windings with stargrounded. The neutral point of the windings is solidly grounded or connected to ground through a current limiting device. The neutral distribution conductor can be:

- Multi-grounded - Earth connected in frequent intervals along the secondary circuits;

- Not connected to earth - Completely isolated and no other earth connection, except at the source;

- Do not grounded - Fully insulated and without intentional grounding. [20]

The distribution feeders in USA are four wires multigrounded or not earthed, and three-wire not earthed (ungrounded).

The connection of distribution transformers in single phase arrays or three-phase is usually grounded wye - delta or delta-delta.

B) Protection and islanding: Multi-grounded four wire systems suffer from overvoltage problems, all sources of DG linked into multi-grounded systems must use protective relays to detect surges.

Although successfully used, overvoltage protection relays in many installations, may allow the occurrence of many cycles of phase to ground overvoltage before the DG is deenergized from the power system with the possibility of damage to DG equipment.

The IEEE 1547-2 standard states that there is no universal requirement for a mandatory isolation device, and also there is no single optimal site for the isolation device [17]. 
C) Automatic reclosing: The standards of service quality highlight the reliability requirements, such as customer minutes of interruption, which motivate the widespread use of automatic reclosing in power systems.

Security and system restoration require the detection of all faults. This also limits the damage to the equipment at fault.

The electric power system that uses automatic reclosing to limit the duration of interruptions to customers, uses devices that can be closed automatically after a failure.

Automatic reclosing systems vary significantly by time, depending on the operation of the electricity system; many use the instantaneous reclosing as an attempt to reclose the circuit breaker or recloser more quickly after the opening due to a failure.

It is highlighted that the reconnection occurs in cycles of 15 to 20 cycles $(0,25 \mathrm{~s}$ to $0,33 \mathrm{~s}$ in $60 \mathrm{~Hz})$, after the failure. It is highlighted that for an intentional island on which the DG energizes the power system, the DG must detect the island and stops energize the power system within 120 cycles (2 seconds) of the characterization of the islanding.

It should be emphasized that the standard states that the utility may require information on the size, location and type of operation of the DG to be installed.

Most operators in the electricity system have a price based on the size or the effect of DG on the insertion site. Thus the owner of DG can choose what best fits him, if sells the excess energy, or sells all power generated by the station.

\section{Comparison of brazilian standards with IEEE 1547-2}

Standards of some Brazilian utilities were briefly mentioned addressing the basic requirements for the insertion of a DG on the network, in sequence was covered some requirements of the IEEE 1547-2 standard for the same situation. After discussed what each standard required is possible to highlight some key points for comparison.

National standards deal with the protection requirements of grounded neutral, isolated neutral with grounded impedance, neutral effectively grounded, 3-wire solidly grounded and isolated. The IEEE 1547-2 standard highlights that their protection should be connected in multi-grounded star when you have three phase four wire, and multi-grounded when two wires single phase.

Brazilian standards emphasize that the connection of distribution transformers with the DG can be Delta (HV) Gounded star (LV), Grounded star (HV) - Delta (LV) and Star - Star. However the IEEE 1547-2 standard points out that can be Grounded star (HV) - Delta (LV) ou Delta (HV) - Delta (LV).

Brazilian regulations state that is not allowed by the power authorities that DG accessing parties meet their islanded load. However, the distributors require to accessing parties that they are prepared to meet loads in some situations of light contingencies. Both standards require that is created a system of protection for islanding event and claim that they are not responsible in case of damage to the equipment on behalf of an islanding. The IEEE 1547-2 standard states that there is no universal requirement for a mandatory isolation device, and also there is no single optimal location for the isolation device.

Brazilian standards emphasize also that it is quite complex the maintenance of AR schemes when distributed generation units connected to the system exist, which can generate risks of a closed switching without synchronization between generators that are meting loads of islanded condition and the utility.

Both standards, national and IEEE Std. 1547-2, highlight the concern with overvoltage, islanding problems, protection devices, and the risks that may occur due to the insertion of DG in its electrical system.

\section{Conclusion}

Due to the increase in technological advances, a trend in spreading the use of DG, increased inclusion of renewables in the energy mix and the reduction of environmental impacts; there is currently a strong trend for consumers to turn into independent power producers, with the consequent search for diversification in the forms of electricity production. With this tendency is natural to search for the quality of the energy provided by new distributed generation systems to local loads and the grid. However, networks are governed by practices and standards related to voltage, frequency, harmonic distortion and power factor. The deviation from the established patterns by these standards featuring an abnormal operating condition, the systems must be able to identify this deviation and stop supplying power to the grid.

The requirements concerning the protection functions are not directly related to the type of DG technology. Both Brazilian and international standards attributes to over frequency, under frequency, overvoltage and under voltage protections the function to prevent islanding.

Concern about the impact of inserting a DG on the network is a constant for all Brazilian and international utilities; however, some standards need to have more detail about such requirements in order to avoid inconsistencies. It is also needed the standardization on the requirements of the protection requirements and how to insert the DG, because there are still some points that Brazilian standards differ from international standards and to make matters worse there is difference in recommendation between the types of transformers connected to the network and its protection philosophy.

A national standardization under the IEEE $1547-2$ optics could facilitate, with respect to the accessing parties orientation for the safe and effective connection of DGs in the network.

\section{Acknowledgement}

The authors acknowledge the financial support from the Universidade Federal do Triângulo Mineiro - UFTM and the Department of Electrical Engineering - DEE. 


\section{References}

[1] Famecos. Wind energy is Option for Distributed Generation. 2013. PUC R Grande do Sul. Accessed in June 10, 2014, in http://eusoufamecos.net/editorialj/eolica. \{In Portuguese \}

[2] ANEEL National Electric Energy Agency (2013). Normative Resolution $n^{o}$ 482. Accessed in June 10, 2014, in http://www.aneel.gov.br/area.cfm?idArea=757\&idPerfil $=2 .\{$ In Portuguese $\}$

[3] National Institute for Energy Efficiency. What is Distributed Generation? Accessed in June 10, 2014, in http://www.inee.org.br/forum_ger_distrib.asp?Cat=gd. \{In Portuguese $\}$

[4] ANEEL National Electric Energy Agency (2013). Generation agent. Accessed in June 10, 2014, in http://www.aneel.gov.br/aplicacoes/AgenteGeracao/agen tegeracao.cfm . \{In Portuguese\}

[5] I. F. E. D. Denis. Methods of Allocation of Losses in Distribution Systems with Distributed Generators. 102 pp. - Doctoral Thesis - School of Electrical Engineering, Universidade Estadual Paulista "Julio de Mesquita Filho”, Ilha Solteira, São Paulo, Brazil, 2003. \{In Portuguese\}

[6] J. T. C. Wright, D. E. de Carvalho \& R. G. Spers. Articles distributed generation disruptive technologies and their future impacts on energy companies.- RAI Journal of Technology Management and Innovation, São Paulo, Brazil v. 6, n. 1, p. 108-125, 2009. \{In Portuguese\}

[7] Brazilian Ministry of Science and Technology, Report prepared for the Ministry of Science and Technology, Project Bra/95/G31. Control no 99/117. United Nations Program for Development Program - PNUD. Accessed in June 10, 2014, in http://www.winrock.org. \{In Portuguese\}

[8] ANEEL - National Electric Energy Agency (2006). BIGGeneration Data Bank. Accessed in June 10, 2014, in http://www.aneel.gov.br/area.cfm?id_area $=15$.

\{In Portuguese\}
[9] ANEEL - National Electric Energy Agency - "Atlas of electricity in Brazil". Accessed in June 10, 2014, in http://www.aneel.gov.br. \{In Portuguese\}

[10] P. H. R. P. Gama, A. R. Aoki, C. M. Luiz, E. Vicentini, M. E. M. de Souza, R. D. Barbosa, T. V. de M. Neto. Working Group C6. 2013. 65 p.. Comparison of the Distribution Companies Requirements for Accessing Parties Entering the Distributed Generation - Cigré Brazil - Brazilian National Committee of Production and Transmission of Electricity - September 2013. IIn Portuguese\}

[11]General Requirements for the Connection of Auto Producer and Independent Power Producer to the CELESC network. $45 \mathrm{p}$. Accessed in June 10, in http://novoportal.celesc.com.br/portal/images/arquivos/ normas/I4320003.pdf. \{In Portuguese\}

[12] Requirements for the Connection of Power Producers to the CEMIG Distribution System. Medium Voltage Connection. 125 p. Accessed in June 10, in http://www.cemig.com.br. \{In Portuguese\}

[13]Microgenerators connection to the COELBA Low Voltage Distribution System. 26 p. Accessed in June 10, in http://tinyurl.com/k4orlzo \{In Portuguese\}

[14]Technical Requirements for the Connection of Generation in Parallel to the COPEL System $18 \mathrm{p}$. Accessed in June 10, in http://tinyurl.com/kqkpkrw. \{In Portuguese\}

[15] Minima Interconnection of Distributed Micro and Mini Generation Requirements with the Distribution Network of AES-ELETROPAULO with Permanent Parallelism Through the Use of Inverters - Medium and Low Voltage Consumers. 22 p. Accessed in June 10, in http://tinyurl.com/nmpaxvr. \{In Portuguese\}

[16] Procedures for the Connection of Micro and Mini Generation to the Light SESA Low Voltage and Medium Voltage Distribution System up to $34.5 \mathrm{kV}$. $41 \mathrm{f}$. Accessed in June 10, in http://tinyurl.com/pd6rs25. IIn Portuguese\}

[17]IEEE- Institute of Electrical and Electronic Engineers Standard for Interconnecting Distributed Resources with Electric Power Systems, 219 pp. IEEE std. 1547-2. 